\title{
PROGNOZOWANIE PROCESÓW FINANSOWYCH ZA POMOCĄ MODELI DYFUZJI
}

\begin{abstract}
$\mathrm{Z}$ a ry s t r e ś c i. Prognozowanie szeregów czasowych jest jednym z najważniejszych zagadnień współczesnej ekonometrii finansowej. W obliczu rosnącego zainteresowania modelami z czasem ciaggłym i szybkiego rozwoju metod ich estymacji, podejmujemy próbę opisu i prognozowania szeregów czasowych z dwóch różnych rynków finansowych za pomocą modeli dyfuzji. W tym celu stosujemy metodę wprowadzoną przez Cziraky i Kucherenko (2008), która bazuje na symulacjach Monte-Carlo. Ponadto porównujemy jakości prognoz otrzymanych za pomoca modeli dyfuzji z uzyskanymi przy użyciu powszechnie stosowanych parametrycznych modeli szeregów czasowych.
\end{abstract}

S ł o w a k 1 u c z o w e: model ARIMA, model GARCH, modele dyfuzji, pierwiastek jednostkowy, prognozy ex post, symulacja Monte-Carlo.

\section{WSTĘP}

Modele z czasem ciagłym oraz ich szczególny przypadek - modele dyfuzji są wyjątkowo ważną klasą modeli wykorzystywanych do opisu procesów finansowych. Obecnie na rozwiniętych rynkach finansowych dostępne są notowania instrumentów finansowych zawierające pełną informację na temat cen transakcyjnych, tzw. dane tick-by-tick. Stanowi to naturalną motywację do stosowania modeli dyfuzji oraz modeli dyfuzji ze skokami w badaniach procesów cen instrumentów finansowych. Modele te zyskały na znaczeniu na początku lat siedemdziesiątych. Wówczas Black i Scholes (1973) wprowadzili model wyceny europejskiej opcji kupna i sprzedaży, w którym cena instrumentu podstawowego opisana była jednym z najprostszych modeli dyfuzji - geometrycznym ruchem Browna. Powstałe w następnych latach modyfikacje modelu Blacka i Scholesa - model Mertona (1974) i Hestona (1993) zakładają odpowiednio, że wolna od ryzyka stopa procentowa i zmienność opisywane są modelami dyfuzji. 
Kolejnym obszarem zastosowań wspomnianych modeli są zagadnienia dotyczące opisu i prognozowania stóp procentowych (struktury terminowej), a także restrukturyzowanych instrumentów dłużnych. Pojawiające się obecnie na rynkach finansowych zaburzenia związane są między innymi z trudnościami dotyczącymi poprawnej wyceny bardzo złożonych instrumentów pochodnych opartych na instrumentach dłużnych. Tematyka ta została podjęta m.in. przez Detemple i Osakwe (1999), którzy zaproponowali model wyceny pojawiających się obecnie w obrocie giełdowym opcji na zmienność, Jagannathana i inni (2004), którzy zastosowali wielowymiarowe modele CIR do wyceny kontraktów cap i swapcji oraz Mannoliniego i in. (2008) wyceniających kontrakty cap i floor za pomocą rozszerzonego modelu CIR.

W niniejszej pracy modele dyfuzji wykorzystano do prognozowania średniej warunkowej logarytmicznych poziomów indeksów giełdowych NASDAQ i WIG20. Parametry oszacowano za pomocą nowoczesnej dwukrokowej metody Phillipsa i Yu (2009) oraz wprowadzonej przez Hansena (1982) uogólnionej metody momentów (GMM). Głównym celem pracy jest ocena jakości prognoz średniej warunkowej otrzymanych za pomocą modeli dyfuzji oraz porównanie ich jakości z prognozami otrzymanymi za pomocą powszechnie stosowanych dyskretnych modeli parametrycznych.

\section{WYBRANE MODELE}

Do modelowania logarytmicznych poziomów indeksów giełdowych wykorzystujemy popularne modele dyfuzji. Większość z nich była pierwotnie stosowana do modelowania stóp procentowych. Istotną cechą wszystkich wykorzystanych w pracy modeli jest własność powracania procesu do średniej.

Najbardziej elementarny z nich, model Vašíčka (1977) zakłada, że proces opisany jest przez następujące stochastyczne równanie różniczkowe

$$
d X_{t}=\kappa\left(\mu-X_{t}\right) d t+\sigma d B_{t}
$$

$\mathrm{z}$ warunkiem początkowym $X_{t_{0}}=x_{0}$, gdzie parametry $\kappa, \mu$ i $\sigma$ przyjmuja wartości dodatnie. Parametr $\mu$ może być interpretowany jako wartość, do której zbiega wartość oczekiwana procesu $X_{t}$ przy $t \rightarrow \infty, \kappa$ - jako tempo powracania procesu do średniej, natomiast $\sigma$ określa zmienność procesu $X_{t}$. Cox, Ingersoll i Ross (1985) zaproponowali następujący model, nazywany w skrócie CIR, będący modyfikacją modelu Vašíčka, w którym proces ceny modelowany jest równaniem

$$
d X_{t}=\kappa\left(\mu-X_{t}\right) d t+\sigma \sqrt{X_{t}} d B_{t}
$$

$\mathrm{z}$ warunkiem początkowym $X_{t_{0}}=x_{0}$. Umieszczenie pierwiastka kwadratowego $\mathrm{w}$ funkcji dyfuzji powoduje, że modelowany proces przyjmuje wartości nie- 
ujemne, jeśli $2 \kappa \mu>\sigma^{2}$. Chan i inni (1992) wprowadzili model, który od pierwszych liter nazwisk autorów został nazywany w skrócie modelem CKLS. Autorzy założyli, że proces modelowany jest przez następujące różniczkowe równanie stochastyczne

$$
d X_{t}=\kappa\left(\mu-X_{t}\right) d t+\sigma X_{t}^{\beta} d B_{t}
$$

z warunkiem początkowym $X_{t_{0}}=x_{0}$, gdzie $\beta \geq 0$ nazywany jest parametrem elastyczności wariancji, natomiast parametry $\kappa, \mu$ i $\sigma$ przyjmują wartości dodatnie i mają taką samą interpretację, jak w wyżej opisanych modelach. Nakładając restrykcje na poszczególne parametry można uzyskać siedem różnych modeli dyfuzji, w tym również przedstawione powyżej modele Vašíčka i CIR (patrz Chan i inni, 1992).

\section{WYZNACZENIE JEDNODNIOWYCH PROGNOZ EX POST Z MODELI DYFUZJI}

Niech $\hat{X}_{t}(l)$ będzie prognozą zmiennej $X_{t+l}$, odpowiadającą błędowi średniokwadratowemu jako funkcji straty. Oznacza to, że prognoza jest zmienną losową dobraną w taki sposób, aby

$$
\mathrm{E}\left[X_{t+l}-\hat{X}_{t}(l)\right]^{2} \leq \min _{g} \mathrm{E}\left[X_{t}-g\left(X_{t}, \ldots, X_{1}\right)\right]^{2},
$$

Gdzie $g\left(X_{t}, \ldots, X_{1}\right)$ jest dowolną funkcją mierzalną względem $\sigma$-ciała generowanego przez informacje na temat procesu do momentu $t$ włącznie. Zmienną $\hat{X}_{t}(l)$ (lub jej realizację) nazywamy prognozą $l$ kroków naprzód zmiennej $X_{t}$. Można wykazać, że

$$
\hat{X}_{t}(h)=\mathrm{E}\left(X_{t+h} \mid \mathrm{F}_{t}\right) .
$$

Wobec tego, jeśli założymy, że badany proces opisany jest modelem dyfuzji, a długość jednego kroku równa jest $h$, to

$$
\begin{aligned}
& \hat{X}_{t}(h)=\mathrm{E}\left[X_{0}+\int_{0}^{t+h \delta} \mu\left(X_{s}, s, \hat{\theta}_{1}\right) d s+\int_{0}^{t+h \delta} \sigma\left(X_{s}, s, \hat{\theta}_{2}\right) d B(s) \mid \mathrm{F}_{t}\right] \\
& =\mathrm{E}\left[X_{t}+\int_{t}^{t+h \delta} \mu\left(X_{s}, s, \hat{\theta}_{1}\right) d s+\int_{t}^{t+h \delta} \sigma\left(X_{s}, s, \hat{\theta}_{2}\right) d B(s)\right] \\
& =X_{t}+\int_{t}^{t+h \delta} \mu\left(X_{s}, s, \hat{\theta}_{1}\right) d s+\mathrm{E} \int_{t}^{t+h \delta} \sigma\left(X_{s}, s, \hat{\theta}_{2}\right) d B(s),
\end{aligned}
$$

gdzie $\hat{\theta}_{1}$ i $\hat{\theta}_{2}$ są, odpowiednio, oszacowaniami wektorów parametrów funkcji dryfu i dyfuzji otrzymanymi na bazie szeregu notowań do chwili $s$ włącznie. 
Biorąc pod uwagę, że notowania dostępne są jedynie w stałych odstępach czasowych, wartość prognozy $\hat{X}_{t}(l)$ aproksymujemy przez następujące wyrażenie

$$
\hat{X}_{t}^{(\delta)}(h)=X_{t}^{(\delta)}+\sum_{k=0}^{h-1} \mu\left(X_{t+k \mid n}^{(\delta)}, t, \hat{\theta}_{1}\right) \delta,+\sum_{k=0}^{h-1} \sigma\left(X_{t+k \mid n}^{(\delta)}, t, \hat{\theta}_{1}\right) \sqrt{\delta} \varepsilon_{t+k}^{(\delta)},
$$

przy czym dla dowolnego $t$ spełniona jest równość $X_{t}^{(\delta)}=X_{[t / \delta]}$. Cziraky i Kucherenko (2008) uzyskują oszacowania $\hat{X}_{t}^{(\delta)}(l)$, symulując niezależnie $N$ $h$-okresowych realizacji wektora innowacji $\left(\varepsilon_{n+1}^{(\delta)}, \ldots, \varepsilon_{n+k}^{(\delta)}\right)$, a następnie za pomocą każdego z nich wyznaczając $h$-okresową trajektorię (7) z warunkiem początkowym $X_{t}^{(\delta)}$. Za oszacowanie $h$-okresowej prognozy przyjmują średnią arytmetyczną z ostatnich wyrazów wszystkich trajektorii.

Za pomoca powyższej metody wyznaczymy jednokrokowe prognozy ex post, czyli prognozy, które są otrzymywane przez dopasowanie modelu na podstawie danych do momentu $T$ włącznie, a następnie obliczania na podstawie otrzymanego w ten sposób modelu, prognoz i reszt od chwili $T+1$ do $T+F$, przy założeniu, że notowanie poprzedzające prognozę jest znane.

\section{PREZENTACJA DANYCH}

Estymacje przeprowadzamy na podstawie dziennych logarytmicznych poziomów indeksu NASDAQ oraz WIG20 z okresu od 2 stycznia 2001 do 29 grudnia 2006 roku. W notowaniach obydwu szeregów nie obserwujemy zmian trendu długookresowego. Przez cały badany okres utrzymuje się trend wzrostowy. Po zlogarytmowaniu szeregów notowań jego znaczenie się marginalizuje. Statystyki opisowe badanych szeregów przedstawione są w tabeli 1.

Tabela 1. Statystyki opisowe logarytmicznych poziomów indeksy NASDAQ oraz WIG20 z okresu od 2 stycznia 2001 do 29 grudnia 2006 roku

\begin{tabular}{cccccccc}
\hline $\begin{array}{c}\text { Szereg } \\
\text { Notowań }\end{array}$ & $\begin{array}{c}\text { liczba } \\
\text { obs. }\end{array}$ & średnia & odch. std. & $\begin{array}{c}\text { skoś- } \\
\text { ność }\end{array}$ & kurtoza & min. & maks. \\
\hline NASDAQ & 1554 & 7,55651 & 0,1818 & $-0,8033$ & 3,0256 & 7,0158 & 7,9583 \\
WIG20 & 1546 & 7,4555 & 0,34958 & 0,4318 & 2,0328 & 6,8979 & 8,1745 \\
\hline
\end{tabular}

Źródło: obliczenia własne.

\section{WYNIKI EMPIRYCZNE}

$\mathrm{W}$ rozdziale tym przedstawiamy wyniki badań dotyczących oceny jakości jednodniowych prognoz ex post otrzymanych za pomocą modeli dyfuzji z parametrami oszacowanymi dwukrokową metodą Phillipsa i Yu (2009) oraz za pomocą wprowadzonej przez Hansena (1982) uogólnionej metody momentów $\mathrm{z}$ macierzą wag wyznaczoną na podstawie jąder Bartletta $\mathrm{z}$ automatycznym do- 
borem parametru wygładzania (Newey i West, 1987). Wartości oszacowań parametrów rozważanych modeli oraz ich błędów standardowych przedstawione są w tabeli 2.

Tabela 2. Wartości oszacowań parametrów modeli dyfuzji oraz ich błędy standardowe. Parametry oszacowane metodą Phillipsa i Yu oraz za pomocą metody GMM. Logarytmiczne poziomy indeksów NASDAQ oraz WIG20

\begin{tabular}{|c|c|c|c|c|c|}
\hline \multirow[b]{2}{*}{ model } & \multirow{2}{*}{$\begin{array}{l}\text { metoda } \\
\text { parametr }\end{array}$} & \multicolumn{2}{|c|}{ Phillipsa i Yu } & \multicolumn{2}{|c|}{ GMM } \\
\hline & & NASDAQ & WIG20 & NASDAQ & WIG20 \\
\hline \multirow[t]{3}{*}{ Vašička } & $\kappa$ & $\begin{array}{c}0,0000258 \\
-\end{array}$ & $\begin{array}{c}0,0012536 \\
-\end{array}$ & $\begin{array}{c}0,91407 \\
(0,65302)\end{array}$ & $\begin{array}{l}-0,12749 \\
(0,29652)\end{array}$ \\
\hline & $\mu$ & $\begin{array}{c}7,5829 \\
-\end{array}$ & $\begin{array}{c}7,4681 \\
-\end{array}$ & $\begin{array}{c}7,5811 \\
(0,011474)\end{array}$ & $\begin{array}{c}6,5984 \\
(119,53)\end{array}$ \\
\hline & $\bar{\sigma}$ & $\begin{array}{c}0,12692 \\
- \\
\end{array}$ & $\begin{array}{c}0,16780 \\
- \\
\end{array}$ & $\begin{array}{c}0,26122 \\
(0,012449) \\
\end{array}$ & $\begin{array}{c}0,23064 \\
(0,0061883) \\
\end{array}$ \\
\hline \multirow[t]{3}{*}{ CIR } & $\kappa$ & $\begin{array}{c}0,081467 \\
-\end{array}$ & $\begin{array}{c}0,00776 \\
-\end{array}$ & $\begin{array}{c}0,91274 \\
(0,65303)\end{array}$ & $\begin{array}{c}-0,13399 \\
(0,29697)\end{array}$ \\
\hline & $\mu$ & $\begin{array}{c}7,5632 \\
-\end{array}$ & $\begin{array}{c}7,3712 \\
-\end{array}$ & $\begin{array}{c}7,5827 \\
(0,011484)\end{array}$ & $\begin{array}{c}6,6412 \\
(2638,9)\end{array}$ \\
\hline & $\sigma$ & $\begin{array}{c}0,045667 \\
-\end{array}$ & $\begin{array}{c}0,052088 \\
-\end{array}$ & $\begin{array}{c}0,094545 \\
(0,0045812)\end{array}$ & $\begin{array}{c}0,084197 \\
(0,0022749)\end{array}$ \\
\hline \multirow[t]{4}{*}{ CKLS } & $\kappa$ & $\begin{array}{c}0,081748 \\
-\end{array}$ & $\begin{array}{c}-0,85398 \\
-\end{array}$ & $\begin{array}{c}0,97411 \\
(0,65404)\end{array}$ & $\begin{array}{c}-0,11478 \\
(0,2995)\end{array}$ \\
\hline & $\mu$ & $\begin{array}{c}7,5632 \\
-\end{array}$ & $\begin{array}{c}6,557 \\
-\end{array}$ & $\begin{array}{c}7,5632 \\
(0,010508)\end{array}$ & $\begin{array}{l}6,5059 \\
(7,471)\end{array}$ \\
\hline & $\sigma$ & $\begin{array}{c}0,72314 \\
- \\
\end{array}$ & $\begin{array}{c}0,4757 \\
- \\
\end{array}$ & $\begin{array}{c}4,5291 \\
(0,0045812)\end{array}$ & $\begin{array}{c}1,7382 \\
(2,3165) \\
\end{array}$ \\
\hline & $\beta$ & $\begin{array}{c}-0,85398 \\
-\end{array}$ & $\begin{array}{c}-0,51843 \\
-\end{array}$ & $\begin{array}{l}-3,7814 \\
(27711)\end{array}$ & $\begin{array}{c}-1,007 \\
(0,66423)\end{array}$ \\
\hline
\end{tabular}

Jako wartości startowe parametrów dryfu przyjęliśmy $\kappa=0$ oraz $\mu$ równe średniej z próby. Za wartość startową dla $\sigma$ w modelach Vašíčka oraz CIR przyjmujemy oszacowanie tego parametru za pomocą estymatora wprowadzonego przez Yoshidę (1992), natomiast w modelu CKLS, dla $\sigma$ przyjmujemy oszacowanie otrzymane uprzednio dla modelu CIR, a dla $\beta, 0,5$.

Źródło: obliczenia własne.

Specyfika metody Phillipsa i Yu uniemożliwia wyznaczenie błędów standardowych. Dlatego w celu oceny jakości parametrów przeprowadzamy symulację Monte Carlo. Za pomocą dyskretyzacji Milsteina zamieniamy równania dyfuzji na odpowiadające im równania różnicowe. Mają one następujące postacie:

$$
X_{n}^{(\delta)}-X_{n-1}^{(\delta)}=\kappa\left(\mu-X_{n-1}^{(\delta)}\right) \delta+\sigma \sqrt{\delta} \varepsilon_{n}^{(\delta)},
$$

dla $n=1,2, \ldots$ z warunkiem początkowym $X_{0}^{(\delta)}$ dla modelu Vašíčka,

$$
X_{n}^{(\delta)}-X_{n-1}^{(\delta)}=\kappa\left(\mu-X_{n-1}^{(\delta)}\right) \delta+\sigma \sqrt{X_{n-1}^{(\delta)}} \delta \varepsilon_{n}^{(\delta)}+\frac{\sigma^{2}}{4} \delta\left(\varepsilon_{n}^{(\delta)}\right)^{2},
$$


dla $n=1,2, \ldots \mathrm{z}$ warunkiem początkowym $X_{0}^{(\delta)}$ dla modelu Coxa, Ingersolla i Rossa oraz

$$
\begin{aligned}
X_{n}^{(\delta)}-X_{n-1}^{(\delta)}= & \kappa\left(\mu-X_{n-1}^{(\delta)}\right) \delta+\sigma\left(X_{n-1}^{(\delta)}\right)^{\beta} \sqrt{\delta} \varepsilon_{n}^{(\delta)} \\
& +\frac{\sigma^{2} \beta}{2}\left(X_{n-1}^{(\delta)}\right)^{2 \beta-1} \delta\left(\varepsilon_{n}^{(\delta)}\right)^{2}
\end{aligned}
$$

dla $n=1,2, \ldots$ z warunkiem początkowym $X_{0}^{(\delta)}$ dla modelu CKLS, gdzie $\varepsilon_{n}^{(\delta)}$ oznacza realizację standardowego białego szumu gaussowskiego. Zakładając, że $X_{0}^{(\delta)}$ jest pierwszą znaną logarytmiczną ceną instrumentu finansowego i za parametry podstawiając wyestymowane wcześniej wartości, generujemy 1000 trajektorii o takiej samej długości jak badany szereg, szacując nowe wartości parametrów dla każdej trajektorii. Średnie i odchylenia standardowe tych oszacowań przedstawione są w poniższej tabeli 3.

Tabela 3. Średnie oraz odchylenia standardowe oszacowań parametrów otrzymanych w wyniku przeprowadzenia 1000 symulacji Monte Carlo dla modelu Vašíčka, CIR i CKLS, z parametrami odpowiadającymi wcześniej otrzymanym oszacowaniom dla poszczególnych szeregów

\begin{tabular}{cccccc}
\hline \multirow{2}{*}{ model } & szereg & \multicolumn{2}{c}{ NASDAQ } & \multicolumn{2}{c}{ WIG20 } \\
\cline { 2 - 6 } Varametr & Średnia & odchylenie std. & średnia & odchylenie std. \\
& $\kappa$ & 0,041843 & 0,05799 & 0,056302 & 0,07403 \\
& $\mu$ & 7,5533 & 0,40102 & 7,4683 & 0,10174 \\
& $\sigma$ & 0,11378 & 0,00343 & 0,15037 & 0,00449 \\
\hline CIR & $\kappa$ & 0,052355 & 0,065201 & 0,052036 & 0,072821 \\
& $\mu$ & 7,7931 & 2,8697 & 7,8626 & 4,9835 \\
& $\sigma$ & 0,040941 & 0,0012372 & 0,046689 & 0,0014052 \\
\hline CKLS & $\kappa$ & 0,04576 & 0,064299 & 0,051807 & 0,067854 \\
& $\mu$ & 8,4942 & 7,3889 & 8,6552 & 8,9667 \\
& $\sigma$ & 0,42524 & 0,00071401 & 0,25744 & 0,0073482 \\
& $\beta$ & 0,14711 & 0,004532 & 0,26598 & 0,011381 \\
\hline
\end{tabular}

Źródło: obliczenia własne.

W oszacowaniach parametrów obserwujemy pewne różnice. Modele, których parametry zostały oszacowane za pomocą uogólnionej metody momentów wskazują na nieco szybszą zbieżność procesu generującego dane do średniej oraz nieco większą zmienność. Jakość dopasowania modelu Vašíčka oraz CIR wydaje się być dość dobra. W większości przypadków wartości błędów standardowych nie są duże, natomiast z przeprowadzonych badań symulacyjnych wynika, że średnie z oszacowań są bliskie rzeczywistym wartościom parametrów, a odchylenia standardowe nie są duże w stosunku do wartości średnich. Dopasowanie modelu CKLS do badanych procesów generujących dane jest nieco gorsze. Oszacowania parametru $\beta$ w modelu CKLS nie są zgodne z jego specyfikacją. Dodatkowo błędy standardowe parametrów dyfuzji są duże, na- 
tomiast średnie z oszacowań tych parametrów w tabeli 3 bardzo odległe od oszacowań otrzymanych dla rzeczywistych procesów.

Dla badanych w pracy szeregów wyznaczyliśmy 100 prognoz ex post. Do wyznaczenia ich wartości użyliśmy 10000 symulacji Monte-Carlo, natomiast do oceny ich jakości wykorzystaliśmy powszechnie stosowane miary błędów. Uzyskanie małych wartości błędów świadczy o satysfakcjonującej jakości prognoz i może sugerować dobre dopasowanie modeli dyfuzji do procesów generujących dzienne ceny logarytmiczne. Dobra jakość prognoz przemawia również za stosowaniem modeli dyfuzji do prognozowania średniej warunkowej jako alternatywy dla parametrycznych modeli szeregów czasowych.

Błędy prognoz zostały porównane $\mathrm{z}$ błędami otrzymanymi dla prognoz pochodzących $\mathrm{z}$ dopasowanych do szeregów powszechnie stosowanych parametrycznych modeli średniej warunkowej, dobranych w taki sposób, aby oszacowania wszystkich parametrów były istotne.

Tabela 4. Wartości błędów prognoz, otrzymanych za pomocą modeli dyfuzji z parametrami oszacowanymi metodą Phillipsa i Yu i metodą GMM oraz przy użyciu parametrycznych modeli średniej warunkowej. Logarytmiczne poziomy indeksu NASDAQ

\begin{tabular}{|c|c|c|c|c|c|c|}
\hline \multirow[t]{2}{*}{ Błąd } & \multicolumn{3}{|c|}{ Metoda Phillipsa i Yu } & \multicolumn{3}{|c|}{ Uogólniona metoda momentów } \\
\hline & Vašiček & CIR & CKLS & Vašiček & CIR & CKLS \\
\hline MSE & $7,3033 e-5$ & $7,3078 \mathrm{e}-5$ & $7,3089 \mathrm{e}-5$ & $7,5079 e-5$ & $7,4249 e-5$ & $7,5569 \mathrm{e}-5$ \\
\hline MedE & $1,8082 e-5$ & $1,7335 e-5$ & $1,8443 e-5$ & $2,1237 e-5$ & $1,9876 e-5$ & $2,1606 \mathrm{e}-5$ \\
\hline ME & 0,055699 & 0,00064038 & 0,055435 & 0,0013926 & 0,0013442 & 0,0015984 \\
\hline MAE & 0,0062114 & 0,0062146 & 0,0062015 & 0,0064573 & 0,0064043 & 0,0065172 \\
\hline RMSE & 0,0085459 & 0,0085486 & 0,0085492 & 0,0086648 & 0,0086168 & 0,008693 \\
\hline MAPE & 0,00079535 & 0,00079575 & $7,9409 \mathrm{e}-6$ & 0,00082676 & 0,00081998 & 0,00083443 \\
\hline AMAPE & 0,00039763 & 0,00039783 & $3,9699 \mathrm{e}-6$ & 0,00041338 & 0,00040998 & 0,00041722 \\
\hline LL & $1,1983 e-6$ & $1,199 \mathrm{e}-6$ & $1,1992 \mathrm{e}-6$ & $1,2319 \mathrm{e}-6$ & $1,2183 e-6$ & $1,24 \mathrm{e}-6$ \\
\hline & \multicolumn{6}{|c|}{ Modele parametryczne } \\
\hline Błąd & \multicolumn{2}{|c|}{$\begin{array}{c}\text { ARIMA }(0,1,2) \\
\text { (Student) }\end{array}$} & $\begin{array}{l}\text { ARIMA(0,1,2) } \\
\text { (GED) }\end{array}$ & \multicolumn{2}{|c|}{$\begin{array}{c}\text { ARIMA }(0,1,2)- \\
\text { GARCH }(1,1) \\
\text { (Student) }\end{array}$} & $\begin{array}{l}\text { ARIMA }(1,1,1)- \\
\text { GARCH(1,1) } \\
\text { (GED) }\end{array}$ \\
\hline MSE & \multicolumn{2}{|c|}{$7,2567 e-5$} & $7,2567 e-5$ & \multicolumn{2}{|c|}{$7,282 \mathrm{e}-5$} & $7,282 e-5$ \\
\hline MedE & \multicolumn{2}{|c|}{$1,7764 \mathrm{e}-5$} & $1,7769 e-5$ & \multicolumn{2}{|c|}{$1,8811 \mathrm{e}-5$} & $1,8819 e-5$ \\
\hline ME & \multicolumn{2}{|c|}{0,056472} & 0,056466 & \multicolumn{2}{|c|}{0,055536} & 0,055532 \\
\hline MAE & \multicolumn{2}{|c|}{0,0062011} & 0,006201 & \multicolumn{2}{|c|}{0,0062328} & 0,0062328 \\
\hline RMSE & \multicolumn{2}{|c|}{0,0085187} & 0,0085186 & \multicolumn{2}{|c|}{0,0085335} & 0,0085334 \\
\hline MAPE & \multicolumn{2}{|c|}{0,00079404} & 0,00079404 & \multicolumn{2}{|c|}{0,00079811} & 0,00079811 \\
\hline AMAPE & \multicolumn{2}{|c|}{0,00039697} & 0,00039697 & \multicolumn{2}{|c|}{0,00039901} & 0,00039901 \\
\hline LL & $1,1907 \mathrm{e}$ & & $1,1907 \mathrm{e}-6$ & $1,1949 \mathrm{e}$ & & $1,1948 \mathrm{e}-6$ \\
\hline
\end{tabular}

Źródło: obliczenia własne. 
Tabela 5. Wartości błędów prognoz, otrzymanych za pomocą modeli dyfuzji z parametrami oszacowanymi metodą Phillipsa i Yu i metodą GMM oraz przy użyciu parametrycznych modeli średniej warunkowej. Logarytmiczne poziomy indeksu WIG20

\begin{tabular}{|c|c|c|c|c|c|c|}
\hline \multirow[t]{2}{*}{ Błąd } & \multicolumn{3}{|c|}{ Metoda Phillipsa i Yu } & \multicolumn{3}{|c|}{ Uogólniona metoda momentów } \\
\hline & Vašiček & CIR & CKLS & Vašiček & CIR & CKLS \\
\hline MSE & 0,00018948 & 0,0001892 & 0,00018936 & 0,00018897 & 0,00018938 & 0,00018973 \\
\hline MedE & $6,1233 e-5$ & $6,3602 e-5$ & $6,5722 \mathrm{e}-5$ & $6,4217 e-5$ & $6,4506 e-5$ & $6,7774 \mathrm{e}-5$ \\
\hline ME & 0,00063017 & 0,00063866 & 0,058766 & 0,0001788 & 0,00032633 & $-0,0001169$ \\
\hline MAE & 0,010608 & 0,010619 & 0,010609 & 0,010582 & 0,010595 & 0,010586 \\
\hline RMSE & 0,013765 & 0,013755 & 0,013761 & 0,013747 & 0,013762 & 0,013774 \\
\hline MAPE & 0,0013032 & 0,0013046 & $1,3034 \mathrm{e}-5$ & 0,0013001 & 0,0013016 & 0,0013007 \\
\hline AMAPE & 0,00065164 & 0,00065232 & $6,5172 \mathrm{e}-6$ & 0,00065007 & 0,00065083 & 0,00065032 \\
\hline \multirow[t]{2}{*}{ LL } & $2,8646 \mathrm{e}-6$ & $2,8603 e-6$ & $2,8627 e-6$ & $2,8568 \mathrm{e}-6$ & $2,8629 \mathrm{e}-6$ & $2,8682 \mathrm{e}-6$ \\
\hline & \multicolumn{6}{|c|}{ Modele parametryczne } \\
\hline Błąd & & $\begin{array}{c}\text { ARMA }(0,2) \\
\text { (GED) }\end{array}$ & & & $\begin{array}{l}\operatorname{ARMA}(1,1) \\
\text { (Student) }\end{array}$ & \\
\hline MSE & & 0,01904131 & & & 0,019061629 & \\
\hline MedE & & 6,6946E-05 & & & $6,87936 \mathrm{e}-5$ & \\
\hline ME & & 0,00035112 & & & 0,000398688 & \\
\hline MAE & & 1,06889157 & & & 1,071935667 & \\
\hline RMSE & & 0,13799026 & & & 0,138063858 & \\
\hline MAPE & & 0,131329 & & & 0,1317012 & \\
\hline AMAPE & & 0,00065666 & & & 0,000658529 & \\
\hline LL & & $2,8789 \mathrm{e}-06$ & & & $2,88198 \mathrm{e}-6$ & \\
\hline
\end{tabular}

W tabelach 4 i 5 MSE oznacza błąd średniokwadratowy, MedE średni błąd medianowy, ME błąd średni, MAE średni błąd bezwzględny, RMSE pierwiastek błędu średniokwadratowego, MAPE średni bezwzględny błą procentowy, AMAPE skorygowany bezwzględny błąd procentowy oraz logarytmiczna funkcję straty (por. Welfe 1998, Doman, Doman 2004).

Źródło: obliczenia własne.

Rząd modelu został określony na podstawie kryterium informacyjnego Schwarza. Występowanie pierwiastka jednostkowego zostało zweryfikowane za pomoca rozszerzonego testu Dickeya-Fullera (Said i Dickey, 1984) oraz Phillipsa i Perrona (1988). W sytuacji gdy brakuje podstaw do odrzucenia hipotezy zerowej o występowaniu pierwiastków jednostkowych, średnią warunkową modelowaliśmy przy użyciu modeli $\operatorname{ARIMA}(p, 1, q)$. Niezależnie wykorzystaliśmy dwa rozkłady innowacji - Studenta oraz GED. Dodatkowo zweryfikowaliśmy występowanie efektu ARCH w badanych szeregach czasowych, stosując w tym celu testy Engle'a (1982) oraz McLeoda, Li (1983). Drugi z nich polega na wykorzystaniu testu autokorelacji Ljunga-Boxa (1978) do kwadratów reszt z modelu liniowego. Wartości błędów prognoz ex post dla badanych szeregów przedstawione są $\mathrm{w}$ tabelach 4 i 5.

Jak łatwo zauważyć, znacznie lepsza jakość prognoz została otrzymana dla cechującego się mniejszą zmiennością szeregu logarytmicznych poziomów NASDAQ. Dla obydwu badanych szeregów przedstawione w tabelach 4 i 5 wartości błędów są zbliżone bez względu na zastosowany model. 
W przypadku logarytmicznych notowań NASDAQ, jakość prognoz otrzymanych za pomocą parametrycznych modeli zmienności jest nieznacznie lepsza, natomiast dla logarytmicznych notowań WIG20 błędy prognoz są nieco mniejsze w przypadku wykorzystania modeli dyfuzji. Spośród modeli dyfuzji, w przypadku szeregu logarytmicznych poziomów NASDAQ, najlepsze prognozy otrzymujemy za pomocą modelu Vašička, natomiast w przypadku indeksu WIG20 za pomocą modelu CIR. Można zauważyć, że błędy prognoz są nieco większe dla modelu CKLS, dla którego, jak już wcześniej zauważyliśmy, wartości oszacowań parametrów nie są zgodne ze specyfikacją modelu a błędy standardowe parametrów dyfuzji duże.

Wartości błędów prognoz otrzymanych za pomocą modeli ARMA oraz ARIMA-GARCH są nieco większe od uzyskanych za pomocą modeli dyfuzji.

\section{PODSUMOWANIE}

Przedstawione wyniki badań sugerują, że jakość prognoz otrzymanych za pomocą modeli dyfuzji dla obydwu badanych szeregów czasowych, jest satysfakcjonująca. Może to sugerować dobre dopasowanie tych modeli do badanych szeregów czasowych. Godnym uwagi jest fakt, że w modelach dyfuzji zmienność uzależniona jest jedynie od czynnika losowego lub dodatkowo od bieżącej wartości procesu. W modelach ARIMA-GARCH zmienność jest opisana oddzielnym równaniem parametrycznym.

Wbrew pierwotnym oczekiwaniom, jakość prognoz z modelu CKLS była nieco słabsza niż z modeli Vašíčka oraz CIR, które są jego szczególnymi przypadkami. Przyczyn takiej sytuacji można się dopatrywać w słabym dopasowaniu tego modelu do badanych procesów generujących dane.

Należy przy tym nadmienić, że wyznaczanie prognoz za pomocą modeli dyfuzji nie jest zagadnieniem bardzo pracochłonnym. Proces ich estymacji za pomoca dwukrokowej metody Phillipsa i Yu trwa zaledwie ułamek sekundy. Estymacja parametrów za pomocą bardziej klasycznej uogólnionej metody momentów trwa również krótko. Najbardziej pracochłonny element procedury - symulacja 10000 trajektorii w celu otrzymania prognoz - również zamyka się maksymalnie w kilku minutach. Wobec powyższego możemy postawić tezę, że modele dyfuzji mogą być wykorzystywane do prognozowania jako dobra alternatywa dla powszechnie stosowanych parametrycznych modeli szeregów czasowych.

\section{LITERATURA}

Black, F., Scholes, M. (1973), The Pricing of Option and Corporate Liabilities, „Journal of Political Economy", 81, 637-659.

Chan K. C., Karolyi G. A., Longstaff F. A., Sanders A. B. (1992), An Empirical Comparison of Alternative Models of Short Term Interest Rates, ,Journal of Finance”, 47, 1209-1227.

Cox J. C., Ingersoll J., Ross S. (1985), A Theory of the Term Structure of Interest Rates, „Econometrica", 53, 385-407. 
Cziraky D., Kucherenko S. (2008), Monte Carlo Forecasting from CIR Square Root Diffusion Models, BRODA Ltd. http://www.broda.co.uk.

Detemple J., Osakwe S. (1999), The Valuation of Volatility Options, „CIRANO Paper, Scientific Series".

Doman M., Doman R. (2004), Ekonometryczne modelowanie dynamiki polskiego rynku finansowego, AE w Poznaniu, Poznań.

Engle R. F. (1982), Autoregressive Conditional Heteroscedacticity with Estimates of the Variance of United Kingsdom Inflation, „Econometrica”, 50, 987-1007.

Hansen L. P. (1982), Large Sample Properties of Generalized Method Of Moments Estimators, „Econometrica”, 50, 1029-1054.

Heston S. L. (1993), A Closed-Form Solution for Options with Stochastic Volatility with Applications to Bond and Currency Options, „The Review of Financial Studies”, 6 (2) 327-343.

Jagannathan R., Kaplin A., Sun S. G. (2004), An Evaluation of Multi-Factor CIR Models Using Libor, Swap Rates, and Cap and Swaption Prices, „Journal of Econometrics”, 116, 113$-146$

Ljung G. M., Box G. E. P. (1978), On a measure of lack of fit in time series models, „Biometrika”, 65, 297-303.

Mannolini A., Mari C., Renò R. (2008), Pricing caps and floors with the extended CIR model, „International Journal of Finance \& Economics”, 13 (4) 386-400.

McLeod A. I., Li W. K. (1983), Diagnostic checking ARMA time series models using squared residual autocorrelations, „Journal of Time Series Analysis”, 4, 269-273.

Merton R. C. (1973), Theory of rational option pricing, „Bell Journal of Economics and Management Science", 4 (1) 141-183.

Merton R. C. (1974), On The Pricing of Corporate Debt: The Risk Structure of Interest Rates, „Journal of Finance”, 29, 449-470.

Newey W.K., West K.D. (1987), A Simple, Positive Semidefinite, Heteroskedasticity and Autocorrelation Consistant Covariance Matrix, „Economerica”, 59, 347-370.

Phillips P. C. B., Perron P. (1988), Testing for a Unit Root in Time Series Regressions, „Biometrika", 75, 335-346.

Phillips P.C.B., Yu J. (2009), A Two-Stage Realized Volatility Approach to Estimation of Diffusion Processes with Discrete Data, ,Journal of Econometrics”, w druku.

Said E., Dickey D.A. (1984), Testing for Unit Roots in Autoregressive Moving Average Models of Unknown Order, „Biometrika”, 71, 599-607.

Vašiček O. (1977), An Equilibrium Characterization of the Term Structure, „Journal of Financial Economics", 5, 177-188.

Yoshida N. (1992), Estimation for Diffusion Processes From Discrete Observation, „Journal of Multivariate Analysis" 41, 220-242.

Welfe A. (1998), Ekonometria, Polskie Wydawnictwo Ekonomiczne, Warszawa.

\section{FORECASTING FINANCIAL PROCESSES BY USING DIFFUSION MODELS}

A b s t r a c t. Time series forecasting is one of the most important issue in the financial econometrics. In the face of grown interest of models with continuous time and quick development of methods of their estimation, we try to use to modeling and forecasting time series from two different financial markets by using diffusion models. We use Monte-Carlo-based method which was introduced by Cziraky i Kucherenko (2008). Quality of received forecasts is confronted with common applied parametrical time series models.

K e y w o r d s: diffusion models, ex post forecasts, Monte-Carlo simulation, the GARCH model, the ARIMA model, unit-root. 